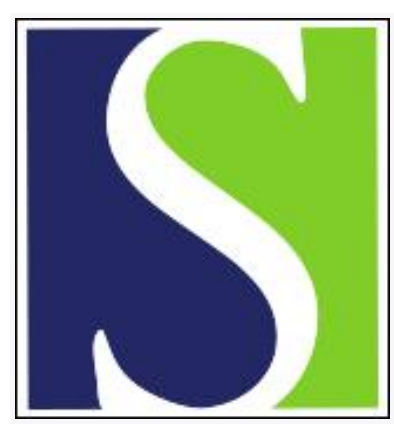

Scand J Work Environ Health 1999;25(6):616-624

https://doi.org/10.5271/sjweh.489

Issue date: Dec 1999

How to deal with stress in organizations? - a health perspective on theory and practice.

by Theorell $\mathrm{T}$

The following article refers to this text: 2001;27(4):258-267

Key terms: cardiovascular disease; decision latitude; evaluation; intervention; job strain; MSD; musculoskeletal disorder; social support

This article in PubMed: www.ncbi.nlm.nih.gov/pubmed/10884162

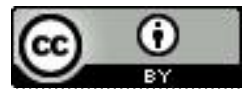




\title{
How to deal with stress in organizations? - a health perspective on theory and practice
}

\author{
by Töres Theorell, $P h D^{1}$
}

\begin{abstract}
Theorell T. How to deal with stress in organizations? - a health perspective on theory and practice. Scand $J$ Work Environ Health 1999;25 (6, special issue):616-624.

This review is focused on organizational aspects of stress reduction. Theoretical models are presented. The association with a few health outcomes (cardiovascular disease, musculoskeletal disorders, and functional gastrointestinal illness) is examined. A few examples of evaluations of health consequences of improved work organization are introduced. Realistic expectations are discussed against the background of etiologic fractions. Concepts like psychological demands, decision latitude, social support, and effort-reward balance or imbalance are discussed and related to practical reorganizational efforts.
\end{abstract}

Key terms cardiovascular disease, decision latitude, evaluation, intervention, job strain, musculoskeletal disorder, social support.

In the whole industrialized world "stress at work" is a growing concern. The labor market is being constantly reorganized, with increasing risk of becoming unemployed for most groups of employees resulting in a lack of basic trust, and there is increasing demands on effectiveness resulting in longer workhours for those who stay employed. Strategies for improving the situation constitute one of the most important themes in occupational health.

Before strategies for improving psychosocial conditions at work are discussed, it is necessary to describe the historical background and the development during recent years with regard to stress at work, and I shall use Sweden as a focus point. Our country has a worklife pattern similar to that of many other western countries. However, Sweden had a long period of beneficial work-environment development that was more abruptly interrupted in the late 1980 s and early 1990 s than in many other countries. This country has been in the forefront of the development of research and intervention in the area of psychosocial factors at work although during recent years this development has slowed down.

Work-environment regulation in Sweden, Norway, and Finland includes psychosocial factors and work organization, along with physical and chemical factors. This step was taken in Sweden in 1976 (1), in legislation which states that psychosocial factors are of the same importance as the physical work environment. In political life, democratization of worklife has been an important part of the agenda for a long time. Accordingly, stress at work has been an important issue in Sweden since the 1970s, particularly among white-collar-worker organizations. Among blue-collar workers, physically adverse conditions were considered more important than psychosocial factors, but explorations of stressful conditions were made already during the 1970 s by the central labor union (LO) in questionnaire surveys. Because of the long historical tradition with regard to the democratization of work in Sweden, stress has been associated with the workers' possibility to influence work conditions. For instance, the central organizations arranged courses for local unions in the introduction of computers and word processing software in offices in the early $1980 \mathrm{~s}$, with the specific aim of increasing the influence of employees.

In the late 1980 s, the government started a special interrogation regarding the most dangerous occupations (2). It stimulated an integration of research in the areas of accident risk, cardiovascular and suicidal epidemiology, and workhours. Stressors considered to be of particular importance have been lack of democracy, poorly organized shiftwork systems, lack of possibility to

Reprint requests to: Dr Töres Theorell, National Institute for Psychosocial Factors and Health, Box 230, S-17177 Stockholm, Sweden. [E-mail: ] 
develop competence, and, especially during the $1990 \mathrm{~s}$, severe systematic maltreatment of employees (bullying).

With regard to most of the physical demands, such as heavy lifting and noise, the conditions in general improved during the period 1975-1995 (3). Also for psychosocial conditions, emotional demands, monotony, and the combination of rushed tempo and monotony, a similar improvement was observed during the 1980s. To some extent this improvement may reflect the rising level of education among the Swedish working population, and to some extent it could also reflect the work environment orientation of Swedish society. It should also be pointed out, however, that more-detailed analyses have shown that there are subgroups of the working population who perceived increasing psychological demands during the 1980s. Longitudinal data published from representative groups of the working population (4) showed that, among women, increasing demands were reported in transportation and health care. Among men the most striking observation was increasing demands in the branches of trade, hotel and restaurant work, transportation, and banking and insurance. These latter observations may show that Swedish worklife began to be affected by new world trends already in the late 1980 s.

The situation has changed drastically during the 1990s. Pressures from the financial markets and Sweden's preparation for joining the European Union (which took place after a referendum in 1994) influenced the politicians to change our tax system, as well as our system for international financial exchange. A financial crisis in Sweden had its peak in the early 1990s. This crisis resulted in a dramatic increase in unemployment rates, to a continuous level of around $10 \%$ from a previous very low level - by European standards - of $3 \%$. It has of course influenced the activities in the work redesign field - when employees fear losing their jobs they may be less willing to discuss work-environment problems. Another important change has been that Swedish governmental support to the occupational health care system (which accounted for $1 / 3$ of the budget in the system) was withdrawn and resulted in a decrease in staff. Thus the occupational health care teams have fewer resources to explore psychosocial work environments and also fewer resources for participation in redesign than previously. There is also more emphasis on financial effectiveness and profit in the system - which means that clients (employers) must buy the services that the occupational health care team provides. Since work-environment explorations, not the least in the psychosocial area, can be perceived as threats to the acting parties at the worksite, there may be less emphasis on preventive work in the future.

The recent trends are reflected in the prevalence of "just-in-time employment" - temporary employment in the form of project employment, practice periods, employment during periods of excessive load, and the like. This prevalence has been rapidly rising in Sweden during the 1990s, despite our emphasis on employment security according to the law. During the period August 1993 to August 1994, 85000 employees lost their permanent employment, while during the same period 100000 men and women became temporarily employed (5). In the present labor-market situation, a division is developing between a "favored" group with stimulating jobs and lifetime job security on one hand and a growing "disfavored" group with psychosocially bad jobs and periods of unemployment interrupted by periods of temporary employment. All of these developments are threatening the basic sense of security and may result in increasing psychosocial tensions.

\section{Swedish job redesign}

As Sweden abandons some of its previous welfare standpoints, there is, at the same time, accumulated experience in job redesign aiming at an improved productivity and psychosocial climate. In order to explore these experiences, an interview study with the management of 2000 worksites was performed (6). The participation rate was $93 \%$. The management interviews were correlated with results from employees in the same worksites participating in the survey of working Swedes performed by Statistics Sweden the same year (AKU, labor market study). The results showed that Swedish management has been greatly influenced by work-organization research and laws. Quality circles and development groups were reported in more than half of the worksites. Industry had the lead in "decentralized responsibility for results" and "wages in relation to flexibility of employees" - which are changes influenced by current economy discussions. Industry, however, also had a good position with regard to possibilities for employees to develop skills and to create equal opportunities for blue-collar and white-collar workers. One of the surprising findings was that "good work" (no excessive demands, good influence over decisions and good opportunities to develop and use skills) was not determined statistically by flattened hierarchy per se. The interpretation of this finding could be that a simplistic application of a flattened hierarchy may not lead to "good work" if it is not coupled with other reorganization efforts as well. In this study conditions were operationally defined for the labeling of a worksite with "new" management and a new work organization. There were 9 conditions - quality circles, thorough introductory courses, planned systematic within-company formal education for at least part of the employees, individual development planning talks with employees, responsibility for results below management level, some degree of 
flexible salaries, decisions about which work tasks to be performed, decisions about how to perform work tasks at least to some extent made below the management level, and decreasing differences between white- collar and blue-collar workers. By adding the number of positive conditions, a measure was created which reflected the degree to which "new" ideas had been instituted. The branches of health care (18\% at least 7 "good" conditions) and trade (17\% at least 7 "good" conditions) had instituted the fewest "new" ideas, and the manufacturing industry (42\% at least 7 "good" conditions) had been the most attentive to them. Another clear result was that small companies had instituted few "new" ideas, while large companies had initiated many.

\section{Psychosocial models for studying stress at work}

The relationship between the psychosocial environment at work and health has attracted considerable attention during recent years. In modern western society this trend seems logical. The increasing complexity of modern society increases the demands upon psychosocial interaction. In several countries an increasing number of employers' unions and trade unions have realized that a functioning psychosocial work environment depends heavily on good work organization. For a long period, however, the theoretical framework for studying stress at work was not useful for redesign. There was a need for sociological theory focusing on the structure of work. The predominant theories in the scientific literature in the 1970s had focused either on individual effort and the interaction between the individual and the environment or on macrosocial phenomena. Few studies had been devoted to the study of effects of structural characteristics of the environment on the health and productivity of the workplace.

An environmental theory that has greatly influenced work redesign efforts in many countries, and particularly in Sweden, was formulated by Karasek (7), who created a 2-dimensional model amalgamating stress research traditions with alienation theory. This theory is discussed in detail since it has had considerable importance in the practice of job redesign. According to Karasek's theory, alienation - in his own terminology lack of decision latitude - interacts with psychological demands in generating long-term effects on health. Excessively high psychological demands are adverse to health only when decision latitude is low. When the decision latitude is high (and the worker can influence decisions regarding how and when to perform work tasks and also develop and use his own skills), excessive psychological demands may not be so harmful. This theory from an early stage incorporated social support at work (8), the importance of which has been discussed by other authors (9). The role of the social support in the demand-control-support model was theoretically developed by Johnson (10). Social support from superiors and workmates could serve as a buffer against the combination of high demands and low decision latitude. The worst combination, iso-strain - high demands, low decision latitude and low support, would have the most adverse health consequences (11).

The importance of various combinations of psychological demands, decision latitude, and social support has been discussed in relation to coronary heart disease (8), acute gastrointestinal functional disorders (12), and musculoskeletal disorders (13). Empirical findings from the majority of a large number of different epidemiologic studies have indicated that there is a clear relationship between low decision latitude and elevated coronary heart disease risk and that excessive psychological demands and low support may add to this risk (14). During later years several studies, particularly those with subjects who retired or became old during the follow-up period and those based upon the less sensitive indirect assessments of work characteristics, have failed to show an association, particularly for psychological demands $(15,16)$. There is a need for improved assessment methods.

Of particular importance to job intervention research is that decreased decision latitude may be associated with increased risk within a 5-year period of development of myocardial infarction among middle-aged men (16). Similar results were found in the British Whitehall prospective study of the onset of new episodes of coronary heart disease among state employees (17). This finding indicates a potential for disease prevention in this group of men through job redesign aiming at preventing decreased decision latitude. With regard to functional gastrointestinal disorders, there is also empirical evidence of a relationship between job strain and the lack of social support on one hand and risk of illness on the other. In the case of musculoskeletal disorders, some studies indicate relationships between illness and excessive psychological demands, while others show relationships between illness and low decision latitude or low social support. The findings depend to a great extent on the samples studied, with different findings for office workers versus manual workers, older versus younger persons, men versus women, and so forth.

The empirical findings on relationships between the demand-control-support model and illness risks indicate that there is a health promotion potential in job redesign aiming at improved decision latitude and social support in workplaces.

The demand-control-support model does not incorporate individual reactions and characteristics. The interaction between the individual and the environment has been explored more systematically in other theoretical 
systems (18-21). Most importantly, there is no empirical evidence that the observed relationships between decision latitude and coronary heart disease risk can be "explained away" by self-selection processes based upon individual personality (which would mean that workers with risk behavior work in the risk occupations). According to this argument, there is reason to believe that collective reorganization may be of importance. On the other hand, it is also clear that some persons will benefit more and others less from social intervention. It is important to take into account published knowledge regarding the interaction between individual people and the environment in the planning of job redesign processes. The health promotion team that follows the demand-controlsupport theory will try by means of job redesign to improve decision latitude and social support and also reduce psychological demands that exceed resources.

Another theoretical model that has been introduced recently is effort-reward (21). It postulates that a high degree of effort has to be paid by increased reward, in the form of remuneration and increased self-esteem and social status. Accordingly, with high effort and low reward more adverse health effects will be observed. This theory incorporates individual attitudes since one of the components in effort is the "intrinsic" effort, which is individually based. There is empirical support for the effort-reward hypothesis, for instance, for civil servants in London (the Whitehall study), who had an elevated risk of developing manifestations of coronary heart disease during follow-up if they reported a poor balance between effort and reward (22). In this study the demand-control and effort-reward models were tested simultaneously, and the results indicated that lack of control and poor effortreward balance were both predictors of increased cardiovascular risk independently of a number of potential confounders, such as smoking, hypertension, and elevated serum lipid levels. Health promotion teams following the effort-reward theory will try to increase all kinds of rewards but will also keep extrinsic and intrinsic efforts on a reasonable level.

What effects can we expect from job redesign based upon either the demand-control-support or the effort-reward theory (or both)? A common way of answering this question is to calculate the etiologic fraction, the proportion of cases with a disease that could have been prevented had the work environment been improved to the level of the "unexposed". The etiologic fraction could be computed if the prevalence of the risk factor $(P)$ is multiplied by the excess risk (RR-1) divided by the relative risk (RR). The etiologic fraction (EF) thus equals $\mathrm{P} \cdot(\mathrm{RR}-1) / \mathrm{RR}$. In the case of psychosocial job conditions there are no absolute exposure risk levels, and accordingly one has to find an operational definition of exposure. For instance, in a study in Stockholm, the ratio between self-reported psychological demands and decision latitude was calculated, and the $25 \%$ with the worst ratio (high demand and low decision latitude) were defined as having been exposed to job strain. They were compared with the remaining subjects. The etiologic fraction (which is based upon the relative risk associated with the risk factor and the prevalence of it) in this case indicates the proportion of first myocardial infarctions that could be prevented if the degree of job strain could be lowered in the exposed group to the level of job strain among others. Several confounders were taken into account, such as smoking, serum lipids, blood pressure, age, and social class. The results indicated that $7 \%$ of the cases among men between 45 and 64 years of age could have been prevented. The proportion was larger among the men between 45 and 54 years of age (11\%). Among working women between 45 and 64 years of age the etiologic fraction was $13 \%$.

These numbers are similar to those reported in other Scandinavian studies $(8,23)$. The etiologic fraction for job strain is lower than that for cigarette smoking but of the same magnitude as that for elevated serum lipids and hypertension. It is important to bear in mind what the etiologic fraction may be, since the intervention can never achieve better results than the etiologic fraction allows them to be. If the effects of job strain, shift work, and effort-reward are independent, the etiologic fraction for improving all these may be very high, probably on the order of $20 \%$.

\section{Techniques for achieving improved decision latitude and social support}

Quality-of-worklife experiments have been going on for at least 2 decades. They have been evaluated in productivity - but not frequently in health terms - and it has been shown that they have been associated very often with a lasting increase in productivity (24). They have been based on the principles that have already been outlined in this paper. An increase in intellectual discretion has been achieved through job enrichment or increased worker responsibility for the complete product. An increase in decision authority has been achieved by means of job enlargement or a flattened organizational hierarchy. An increase in social support, finally, has been achieved by means of improved feedback and the formation of more cohesive work groups. During later years, in both North America and Scandinavia, the starting of regular staff meetings for the systematic discussion of important decisions regarding work routines and goals has been used as a tool for increased decision latitude and social support.

The occupational health care team has often been an important vehicle in Scandinavian job redesign (25). The 
occupational health care team has the possibility to work both with the structure of the company and the individual workers. It has the possibility to carry out individual measurements of psychological and somatic health indicators and to monitor these through the change process. It has been the experience of health-oriented job redesigners that the concomitant emphasis on structure and individuals is helpful both for individual motivation to follow health promotion advice (which is strengthened when workers discover that there is willingness in management to improve the structure) and for success in instituting structural change (which will benefit from the engagement of individuals and their health problems).

Even in Sweden with its long tradition of work redesign, very few studies have actually documented the health consequences of this type of job intervention. Most of the published studies have been based upon self-administered questionnaires. One study of cardiovascular risk factors (26) showed that a similar program (which was evaluated in a controlled study) was followed by a reduced ratio of low-density to high-density lipoprotein cholesterol in the experimental group but not in the comparison group. The improvement amounted to $6 \%-$ which should be related to the etiologic fraction associated with job strain - accordingly not a bad result! As in all experiments of this kind, the design was not "clean" in the sense that all other changes had been ruled out, but the findings could be interpreted to mean that job redesign aiming at improved social relationships and decision latitude could lead to decreased cardiovascular risk. In that study, it was also shown that the psychosocial job changes were more beneficial in worksites which had an active attitude toward the change (27). In those with a more passive attitude, feedback from superiors deteriorated and the psychoendocrinological arousal - as reflected in serum cortisol levels during the intervention - was more pronounced.

Psychosomatic symptoms, such as gastrointestinal symptoms, tiredness, and depression, reportedly decreased among employees in part of the Volvo company after a number of psychosocially oriented job changes had been instituted, such as role change among supervisors in the direction of more facilitation, a less authoritarian leadership style, promotion of personal contact between customers and employees, and increased teamwork $(25,28)$.

\section{Evaluation of practical experiments}

The redesign process has been described in many case studies. The health consequences of improved work organization, however, have been in scientific focus in a few published studies. Experiences in all the countries of the European Union have recently been summarized (29). Evaluations of systematic efforts to improve work conditions by increased decision latitude, support, and reward, in order to improve health, are more common in the northern countries (Finland and Sweden, for instance) than in central Europe.

One practical Swedish example in the European summary is an intervention in mail delivery in a region north of Stockholm $(30,31)$. The job redesign processes were prompted by current demands for effectiveness and speed in public service, but also by concerns caused by a high sick-leave prevalence among the employees. Mail delivery is a physically demanding job. The relative physical demand increases with increasing age. Accordingly it is uncommon to work as a mail carrier after the age of 50 years. The traditional means of reducing physical demand has been to reduce ergonomic load. There is also a possibility to change the work organization, however, since increased variation may reduce tissue strain and an improved psychosocial climate may decrease vulnerability (13). The evaluation was based upon a comparison of 2 stations which started at the same time. Their start was prompted by a need to split 1 district station into 2 because of the growing population in the area. The traditional station was located on the original site. Both stations were rebuilt, and accordingly physical environmental changes were made in both. Employees could select the station they wanted to work in themselves. The selection of study subjects into the 2 groups was therefore not random, but most of the choices were based upon external factors such as closeness to home.

The most important difference between the 2 worksites was that the foremen in the modern station had greater responsibility than those in the traditional one. Another important difference was that the employees in the modern station had joint responsibility for all the districts of the team, whereas they had responsibility only for their own district in the traditional station. In the modern station the teams also had joint responsibility for partially new work tasks. Cohesiveness was strengthened in this station by a team-based bonus system.

In the mail delivery service it was possible to perform a before-after comparison both in the intervention group and in the group with less extensive intervention. Measurements were performed before the intervention and 12 months later (1991 and 1992)

According to the questionnaires, the ergonomic conditions did not change significantly. Social support increased significantly in the modern station only, and psychological demands decreased significantly in both stations. Authority over decisions increased in the traditional station but not in the modern one - somewhat contrary to expectations. A combined index of neck, shoulder, and chest back pain, as well as shoulder and chest back pain, decreased significantly in the modern station but not in 
the traditional one. The benefit with regard to prevalence was $13 \%(25 \%$ in the modern station and $12 \%$ in the traditional station). The favorable musculoskeletal changes were more pronounced for participants below the age of 35 years than among those above this age.

\section{Comments on the practical example}

The evaluation of the mail delivery intervention was not optimal -2 randomly selected samples were not followed and compared with regard to outcome after the intervention. The 2 groups were self-selected, and there is a possibility that more healthy and satisfied workers could have selected 1 of the 2 alternative stations. The available information speaks against this interpretation, however.

The theoretical background of the instituted changes was the demand-control-support model $(8,10)$. The foremen were given increased authority in both stations but particularly so in the modern station. Since the foremen were closer to the individual delivery workers, this change could have resulted in improved authority over decisions. In both cases the organizational changes could also have resulted in improved intellectual discretion.

The other main emphasis was on improved social support and climate. Improved social support is often difficult to disentangle from increased authority over decisions. Often an improved sense of individual control is obtained by collective actions of the total work group. The tool was the formation of groups with joint responsibility for several districts, allocation of these groups to separate rooms, and financial group bonus.

In several previous experiments, effects have been documented after group feedback and group intervention on either different aspects of authority over decisions or intellectual discretion $(8 \mathrm{p} 211,32)$ or social support (26, 27). In previously published experiments, decreased ( $8 \mathrm{p}$ $211,26)$, as well as increased (32), psychological demands have been reported following the changes. In the present case study no consistent finding was made from this point of view - decreased demands in both the traditional and the modern station in the delivery experiment. The organizational outcome depends on initial problems, work content, and strategy for change. Silverstein (33) has discussed the problems of scientific evaluations of ergonomic changes. In such changes, as in psychosocial redesign experiments, well-controlled comparisons of comparable randomly selected groups are usually not feasible. The recommended strategy is for the researchers to use all practical experiments and to try to evaluate them as thoroughly as possible, without demands for perfect comparability of study groups. The more published evaluations we get, the more possibility we have to make correct interpretations.
The main health outcome result in the mail delivery stations was that neck, shoulder, chest, and back pain decreased. This finding is consistent with observations indicating that good social support at work may have a statistically significant protective effect in relation to musculoskeletal disorders $(34,35)$.

Recently a comparison was published between 2 different forms of work organization in industry (36) - a traditional assembly line and a new and more flexible organization with small autonomous groups having a greater possibility to influence the pace and content of their work. The analyses showed that self-reports and physiological parameters (blood pressure, heart rate and urinary excretion of adrenaline) showed stronger reactions - corresponding to increased fatigue and energy mobilization - during the work shift in the conventional assembly-line work organization. the subjects in this group furthermore seemed to be slower in unwinding after work than those in the new flexible organization. This study seems to verify the importance of decision latitude in industrial work.

\section{General points of view}

In the Scandinavian setting, considerable experience has been built up regarding the knowhow of instituting job organization improvements. The large occupational health care organizations, such as the organization for state employees, have formulated strategies for this procedure in manuals. The most important principles are the following:

1. Job changes require considerable time. Already when an exploration (which is always regarded by the employees as a start of a change process) is planned, the team must have resources and allocate time to the follow-up of the consequences. Social changes always take more time than expected! Months and years rather than days and weeks are required.

2. Different groups of actors have to be informed well in advance before and continuously during the process. Processes that arise as needs formulated by the workers are always more likely to be successful than top-down processes! [See, for instance, Gustavsen \& Hunnius (37)]. The managers and superiors have to be informed regarding important findings and developments during the process, for instance, when group feedback is planned.

3. Group feedback and discussion are important components in the change process. The importance of group feedback is illustrated by the findings in a study of 6 occupational groups, with each participant being monitored on 4 occasions during a year. Very small changes in the perceived work environment were reported in relation to 
the individual feedback occasions. After group feedback had taken place, on the other hand, measurements indicated that psychological demands had decreased and intellectual discretion had increased significantly. More conflicts and more awareness of work environment problems were also reported after the group feedback occasion (8).

Group feedback and discussion have to be organized systematically. What is found in the exploration is compared with other groups, which are used for reference. Both strengths and weaknesses are identified. The positive aspects are important since the workers need pride and self-esteem. But the worksite has to identify problems that are important to ameliorate. In the ideal situation, special employees are elected who have the task (within a specified time frame) of formulating practical solutions. These solutions are discussed on the next occasion. Several such groups can work concomitantly on different specified problems.

4. Mental preparation is needed for conflicting opinions about solutions. After the initial phases of "engagement" and "search", the "change" phase occurs. During this phase there are always different opinions about solutions. If the initiators of the process are unprepared for this diversity of opinions (and potential serious conflicts!), they may not facilitate the redesign in a helpful manner.

5. Concomitant work must take place between the individual workers and the organization. Common wisdom in practical stress intervention at worksites is that workers are more motivated to join the reorganization process if their individual stress factors are monitored along with those of the total organization. Feedback should preferably take place on both the individual and the group level. The individual effects of the program are strengthened by the group feedback and vice versa. This result has been described by several groups who have established worksite stress management techniques $(8,25)$

\section{International perspectives}

The perspective so far has been narrowed to Sweden. The phenomena that have been discussed are being widely discussed in the whole industrialized world, however. Increasing demands are reported in many countries. In the United States there was a clear increase between 1977 and 1997 in the proportion of workers reporting that they "work very fast" - from $55 \%$ to $68 \%$. Furthermore, the proportion of workers who report that they "never have enough time to get everything done on the job" has increased from $40 \%$ to $60 \%$ during the same period. The same survey indicated that the average number of weekly workhours including nonpaid hours has increased by
3.5 to 47.1 hours from 1977 to 1997 (38). In Europe during the period 1991 to 1996 there was a considerable increase in reported demands. "High speed work" was reported by 35\% in 1991 and 43\% in 1996 and "tight deadlines" by $38 \%$ in 1991 and by $45 \%$ in 1996 (39). In Europe, in 1996, $23 \%$ of workers were working more than 45 hours per week (40). Although according to the same reviews there has been an increase in autonomy at work both in Europe and in the United States, the increase has not been sufficient to outweigh the increasing demands. In Europe the proportion of high-strain jobs increased from about $25 \%$ in 1991 to about $30 \%$ in 1996 (39).

Extensive discussions are ongoing regarding the possibility of increasing demands and effectiveness by empowerment in "lean production". A recent review of all published studies (41) has indicated that this change is not possible and that lean production mostly leads to elevated demand levels, modest or no improvements in decision latitude, and adverse health effects. It is possible that the limits of psychological demands have been neglected in many lean-production systems. There are various systems for increasing effectiveness, however. Scandinavian "sociotechnical systems" are more oriented towards group decision making, long cycle time, and autonomy than other systems are. The review also points at the necessity of informing the workers and entering into discussions with them when changes are instituted (40). The examples that have been used in the present review illustrate these points.

The European review on the prevention of stress with improved productivity shows that the perspectives are different in different countries within Europe (29). In general the studied intervention has had both an individual and an environmental perspective. In one of the countries the environmental perspective only dealt with ergonomics and technology, while the bulk of the described project was directed towards improved individual training. In most projects in the European countries, however, intervention aimed at an improved psychosocial environment was an integrated part of the program. It has been observed by practitioners in the whole world that individual training programs have a more longlasting effect if they are coupled with environmental programs. People who are trained in stress management techniques, for instance, will have pronounced difficulties to use their new knowledge if the work environment they return to is hostile to it. Vice versa, an environmental program will be more likely to succeed if it is coupled with individual counseling.

\section{Concluding remarks}

This review and the case descriptions illustrate that work redesign for the improvement of the psychosocial 
environment has had a strong position in Sweden's worklife for a long time. Swedes have gathered experiences and knowhow. Due to a recent societal financial crisis, however, health promotion in relation to work organization has had a weaker position during later years. The case descriptions illustrate that it is possible to improve the work organization of public services and that such changes may benefit employee health.

\section{References}

1. Arbetsmiljölag 1976 [Swedish law on work environment]. Stockholm: Sweden Statens Offentliga Utredningar, 1976:1.

2. Arbetsmiljökommissionen [Governmental Commission on Work Environment]. Arbeten utsatta för särskilda hälsorisker [Occupations exposed to pronounced health risks] Allmänna förlaget. Stockholm: Gotab, 1989.

3. Statistics Sweden. Välfärd och jämlikhet i 20-årspespektiv 1975-1995 [Welfare and social equity in twenty years' perspective 1975-1995]. Stockholm: Statistics Sweden, 1997. Report 91.

4. Fritzell J, Lundberg O. Vardagens villkor [Conditions of everyday life]. Stockholm: Bromberg, 1994.

5. Aronsson G, Sjögren A. Samhällsomvandling och arbetsliv: omvärldsanalys inför 2000-talet [Societal change and working life: analysis of the international perspective facing year 2000]. Solna (Sweden): Arbetsmiljöinstitutet, 1994

6. Le Grand C, Szulkin R, Tåhlin M, editors. Sveriges arbetsplatser - organisation, personalutveckling, styrning [Sweden's work places - organisation, personnel development and management]. Stockholm: Studieförbundet Näringstir och Samhälle, 1993

7. Karasek RA. Job demands, job decision latitude and mental strain: implications for job redesign. Adm Sci Q 1979;24:285-307.

8. Karasek RA, Theorell T. Healthy work. New York (NY): Basic Books, 1990.

9. House J. Work, stress and social support. Reading (MA) Addison-Wesley, 1981.

10. Johnson JV, Hall EM. Job strain, work place social support and cardiovascular disease: a cross-sectional study of a random sample of the Swedish working population. Am J Public Health 1988;78:1336-42.

11. Johnson JV, Hall EM, Theorell T. Combined effects of job strain and social isolation on cardiovascular disease morbidity and mortality in a random sample of the Swedish male working population. Scand J Work Environ Health 1989;15:2719.

12. Westerberg $\mathrm{L}$, Theorell $\mathrm{T}$. Working conditions and family situation in relation to functional gastrointestinal disorders. Scand J Prim Health Care 1997;15:76-81.

13. Theorell T: Possible mechanisms behind the relationship between the demand-control-support model and disorders of the locomotor system. In: Moon SD, Sauter SL, editors. Beyond biomechanics: psychosocial aspects of musculoskeletal disorders in office work. London: Taylor and Francis, 1996:6574.

14. Theorell T, Karasek RA. Current issues relating to psychosocial job strain and cardiovascular disease research. J Occup
Health Psychol 1996;1:9-26.

15. Johnson JV, Stewart W, Hall EM, Fredlund P, Theorell T. Long-term psychosocial work environment and cardiovascular mortality among Swedish men. Am J Public Health 1996;86:324-31.

16. Theorell T, Tsutsumi A, Hallquist J, Reuterwall C, Fredlund $P$, Emlund N, et al. Decision latitude, job strain and myocardial infarction. Am J Public Health 1998;88:382-8.

17. Marmot M, Bosma $\mathrm{H}$, Hemingway $\mathrm{H}$, Brunner E, Stansfeld $\mathrm{S}$. Contribution of job control and other risk factors to social variations in coronary heart disease incidence. Lancet 1997;350:235-9.

18. Cooper CL, Marshall J. Occupational sources of stress: a review of the literature relating to coronary heart disease and mental ill health. J Occup Psychol 1976;49:11—28.

19. French JRP. The social environment and mental health. J Soc Issues 1963;19:39-56.

20. Katz D, Kahn R. Social psychology of organizations. New York (NY): Wiley, 1966.

21. Siegrist J. Adverse health effects of high effort/low reward conditions. J Occup Health Psychol 1996;1:27-41.

22. Bosma H, Peter R, Siegrist J, Marmot M. Two alternative job stress models and the risk of coronary heart disease. Am J Public Health 1998;88:68-74.

23. Olsen O, Söndergaard-Kristensen T. Cardiovascular illness and work environment, part 3: what relative importance has the work environment to cardiovascular illnesses in Denmark? Copenhagen: Arbejdsmiljöfondet, 1988.

24. Kopelman RE. Redesign and productivity: a review of the evidence. Nat Prod Rev 1985(summer):237-55.

25. Wallin L, Wright I. Psychosocial aspects of the work environment: a group approach. J Occup Med 1986;28:384-93

26. Orth-Gomér K, Eriksson I, Moser V, Theorell T, Fredlund P. Lipid lowering through stress management. Int $\mathrm{J}$ Behav Med 1994;1:204-14

27. Theorell T, Orth-Gomér K, Moser V, Undén A-L, Eriksson I. Endocrine markers during a job intervention. Work Stress 1995;9:67-76.

28. Plate R, Gall I, Schütz F. Ny syn på produktionen [New view of production]. In: En bok om Volvo [A book about Volvo]. Göteborg: AB Volvo, 1985.

29. Kompier M, Cooper C. Preventing stress, improving productivity: European case studies in the workplace. London: Routledge, 1999.

30. Theorell $\mathrm{T}$, Wahlstedt $\mathrm{K}$. Sweden: mail processing. In: Kompier M, Cooper C, editors. Preventing stress, improving productivity: European case studies in the workplace. London: Routledge, 1999:195-221.

31. Wahlstedt $\mathrm{K}$, Nygård $\mathrm{CH}$, Kemmlert $\mathrm{K}$, Torgén $\mathrm{M}$, Gerner Björkstén M. Påverkan av en organisationsförändring på arbetsmiljöfaktorer och upplevd hälsa inom brevbäring. [Influence of an organizational change on work environment and perceived health in mail delivery]. Solna (Sweden): Arbetslivsinstitutet, 1996:1-29. Arbete och hälsa 15.

32. Gardell B, Svensson L. Medbestämmande och självstyre: en lokal facklig strategi för demokratisering av arbetsplatsen [Worker participation and autonomy: a local union strategy for democratization of the workplace]. Stockholm: Prisma, 1981.

33. Silverstein B. Design and evaluation of interventions to reduce work-related musculoskeletal disorders: lecture at PREMUS, Stockholm 1992. Solna: Arbetslivsinstitutet, 1992:17. Arbete och Hälsa 17.

34. Ahlberg-Hultén GK, Theorell T, Sigala F. Social support, job 
strain and musculoskeletal pain among female health care personnel. Scand J Work Environ Health 1995;21:435-9.

35. Bongers PM, de Winter CR, Kompier MAJ, Hildebrandt VH. Psychosocial factors at work and musculoskeletal disease [review]. Scand J Work Environ Health 1993;19:297-312.

36. Melin B, Lundberg U, Söderlund J, Granqvist M. Psychologi$\mathrm{cal}$ and physiological stress reactions of male and female assmbly workers: a comparison between two different forms of work organisation. J Organ Behav 1999;20:47-61.

37. Gustavsen B, Hunnius G. New patterns of work reform: thecaseofNorway. Oslo: Oslo University Press, 1981.
38. Bond JT, Galinsky E, Swanberg JE. The 1997 national study of the changing workforce. New York (NY): Families and Work Institute, 1998.

39. Paoli P. Second European survey on the work environment European foundation 1996. Dublin: European Foundation for the Improvement of Living and Working Conditions, 1997.

30. Walters D. Health and safety strategies in a changing Europe. Int J Health Serv 1998;28:305-31.

41. Landsbergis P, Cahill J, Schnall P. The impact of lean production and related new system of work organization on worker health. J Occup Health Psychol 1999;4:108-30. 